\title{
A Different Origin of the Right Gastro-omental Artery
}

\author{
Un Origen Diferente de la Arteria Gastro-omental Derecha
} Aldo Okamura*; Daniela Alvarez*; Paula Genovez*; Eduardo José Caldeira**;
Marcelo Rodrigues da Cunha* ; Cesar Alexandre Fabrega Carvalho****

OKAMura, A.; Alvarez, D.; GenOVez, P.; CAldeira, E. J.; DA CUNHA, M. R. \& CARVALHO, C. A. F. A different origin of the right gastro-omental artery. Int. J. Morphol., 33(4):1343-1347, 2015.

SUMMARY: The gastro-omental artery is one of the branches of the common hepatic artery. Alterations in the embryonic development of the ventral splanchnic arteries can cause marked variations. A rare variant of the right gastro-omental artery was observed during dissection of a 50-year-old male cadaver. The occurrence of this variant has not been reported in the specialized literature. This case of a different origin of the gastro-omental artery is described in detail in order to provide information that may contribute to upper abdominal surgeries.

KEY WORDS: Right gastro-omental artery; Anatomical variations; Abdominal surgeries.

\section{INTRODUCCIÓN}

The abdominal aorta begins at the aortic hiatus of the diaphragm, anterior to the $12^{\text {th }}$ thoracic vertebra. It has several branches that can be divided into the ventral, lateral, dorsal, and terminal branch. The ventral and lateral branches are distributed to the viscera. The dorsal branches supply blood to the body wall, vertebral column, vertebral canal, and its content (Williams et al., 1989). The celiac trunk is a wide $1.25 \mathrm{~cm}$ long ventral branch located just below the aortic hiatus. The diameter of this trunk ranges from 8 to 40 $\mathrm{mm}$ (Michels, 1951). The main branches of the celiac trunk that can be usually identified are the left gastric, splenic and common hepatic arteries. The trifurcation of the celiac trunk was first described by Haller (1756). In an angiographic study, Vandamme \& Bonte (1985) showed that only $86 \%$ of the celiac trunk contained the classical trifurcation. Many variants of the celiac trunk have been described. For example, only two of the classical branches of the trunk may be present (Vandamme \& Bonte; Shoumura et al., 1991; Harada et al., 1997; Kahraman et al., 2001; Nakamura et al., 2003; Saeed et al., 2003): a) a gastrolienal trunk occurs when the hepatic artery arises from the superior mesenteric artery or the aorta; b) a hepatolienal trunk is present when the left gastric artery originates directly from the aorta; c) a hepatogastric trunk occurs when the splenic artery originates from the aorta or the superior mesenteric artery. In some cases, the trunk itself may be absent and its branches then arise from the aorta (Morettin et al., 1965; Okada et al., 1983; Vandamme
\& Bonte; Basar et al., 1995; Yamaka et al., 1985). In rare cases, the celiac trunk and the superior mesenteric artery can be fused to a celiacomesenteric trunk (Cavdar et al., 1997; Detroux et al., 1998; Agarwal et al., 2000). The aim of this study was to describe the rare occurring gastroomental artery variation, which can be a guide and precaution during operative procedures in the region.

\section{CASE REPORT}

A rare variant of the right gastroepiploic artery was observed during dissection of a 50-year-old male cadaver. A detailed anatomical descriptions of this rare case is provided.

A gastrosplenic trunk (GST) and another hepatomesenteric trunk (HMT) arose from the ventral side of the aorta (Figs. 1C and 2). The GST was situated at the L1 level at a distance of $0.3 \mathrm{~cm}$ from the tendinous arch of the diaphragm (Figs. 1C and 2). In contrast, the HMT was located at the L1-L2 intervertebral level at a distance of 1.3 $\mathrm{cm}$. The GST was $0.4 \mathrm{~cm}$ long. With a short and anterior course, this trunk gave origin to the following arteries: left gastric artery $(\varnothing 0.3 \mathrm{~cm})$, splenic artery $(\varnothing 0.4 \mathrm{~cm})$, and an aberrant artery whose irrigation territory corresponded to that of the gastro-omental artery $(\varnothing 0.4 \mathrm{~cm})$ (Figs. 1B and 2). 


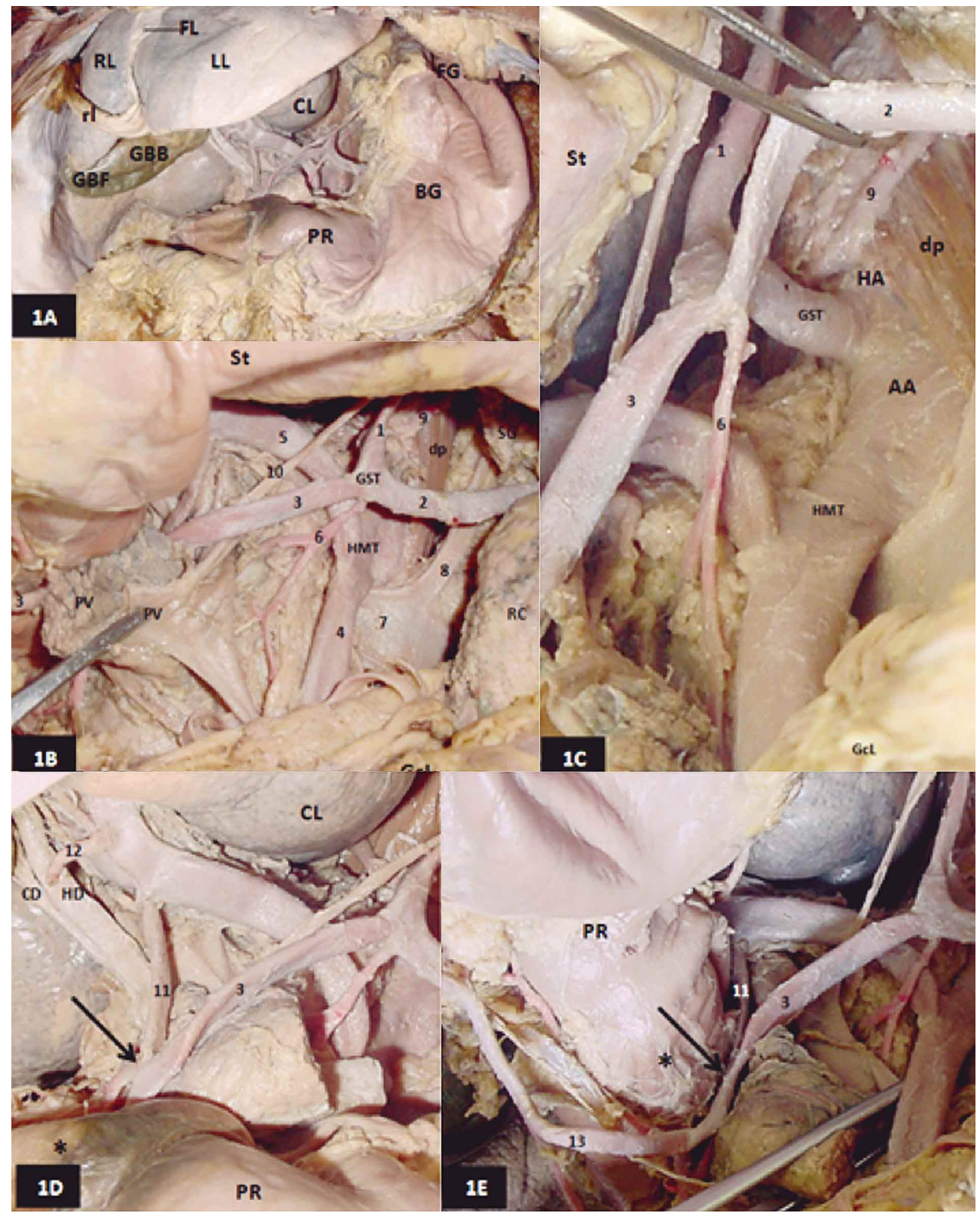

Fig. 1. A) Overall anterior-inferior view of the supramesocolic compartment. Note in the hepatic compartment: the right (RL), left (LL) and caudate (CL) lobes and falciform (FL) and round (RL) ligaments. Fundus (GBF) and body (GBB) of the gallbladder. Note the fundus (FG), body (BG) and pyloric region (PR) in the gastric compartment. B) Anterior view. The gastrocolic ligament (GcL) was dissected and the stomach (St) was separated cranially to show the celiac compartment. Note the gastrosplenic trunk (GST) with its left gastric (1) and splenic (2) branches. Observe the aberrant branch (3) and its caliber, which is practically the same as that seen at its origin, i.e., the splenic artery. Note the superior mesenteric (4) and common hepatic (5) branches of the hepatomesenteric (HMT) trunk. Forceps separating the portal vein (PV) and body of pancreas (P) for demonstration of the superior mesenteric artery (4), dorsal pancreatic artery (6), left renal vein (7), and left suprarenal vein (8). Suprarenal gland (SG); left renal capsule (RC); left medial pillar of the diaphragm muscle (dp); left inferior phrenic artery (9); left gastric vein (10). C) Detail of the celiac compartment. Abdominal aorta (AA); aortic hiatus (HA); left medial pillar of the diaphragm muscle (dp); left inferior phrenic artery (9). The splenic artery (2) was dissected for demonstration of the gastrosplenic trunk (GST). Left gastric artery (1); aberrant branch (3) of the splenic artery (2); hepatomesenteric trunk (HMT) with its superior mesenteric (4) and common hepatic (5) branches; stomach (St); dissected gastrocolic ligament (GcL); dorsal pancreatic artery (6). D) Detail of the content of the dissected hepatoduodenal ligament, showing the side-to-side anastomosis (arrow) between the aberrant branch (3) and the gastroduodenal artery (11). Dissected right gastric artery (12); common hepatic duct (HD); cystic duct (CD); caudate lobe (CL); pyloric region (RP); duodenal bulb (*). E) Cranially separated stomach showing the course of the aberrant branch (3) and after anastomosis (arrow) with the gastroduodenal artery (11) and following the course and relationships of the right gastro-omental artery (13). 


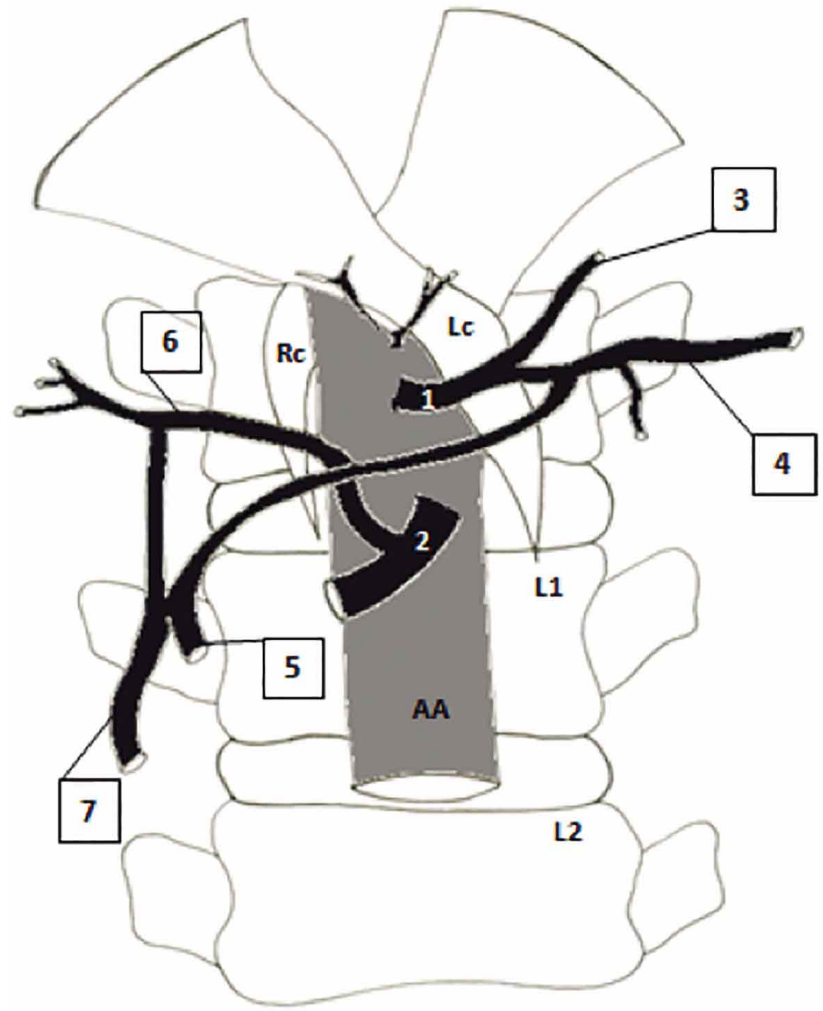

Fig. 2. A schematic drawing showing the different origin of the right gastroepiploic artery. Also the attachments of the right (Rc) and left crus (Lc) to L1 and L2 lumbar vertebra levels. Gastrosplenic trunk (1); Hepatomesenteric trunk (2); Left gastric artery (3); Splenic artery (4); Common hepatic artery (5); Anastomose (arrow) side-to-side between aberrant branch (6) and gastroduodenal artery (7) and Gastroepiploic artery (8).
This artery went to the right, crossing anteriorly the hepatic branch $(\varnothing 0.4 \mathrm{~cm})$ of the HMT, and anastomosed side-toside with the gastroduodenal artery $(\varnothing 0.2 \mathrm{~cm})$ and subsequently with the duodenal bulb (Figs. 1D, 1E and 2). Next, this artery followed an anterior course to the left at the cranial margin of the greater omentum along the greater curvature of the stomach (Fig. 1E).

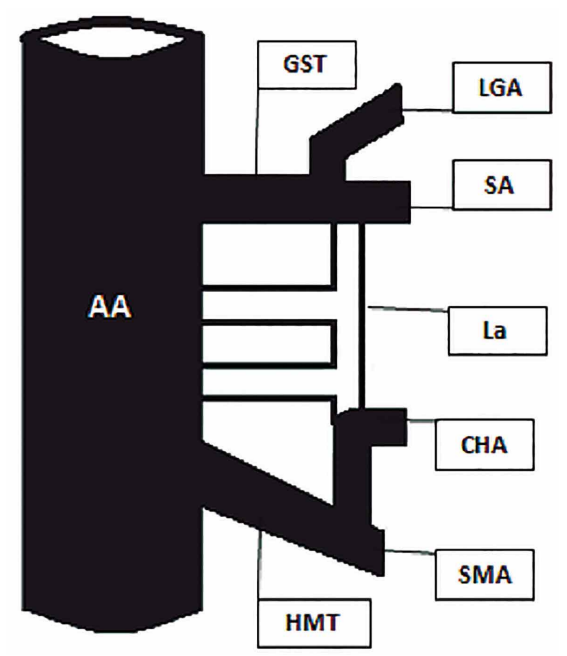

Fig. 3. A schematic drawing showing embryological development of the celiacomesenteric type IV.1 according to Morita, (1935). Gastrosplenic and (GST), hepatomesenteric (HMT) trunks. Left gastric artery (LGA); Splenic artery (SA); Ventral langsanastomose (La); Common hepatic artery (CHA); Superior mesenteric artery (SMA) and Abdominal Aorta (AA).

\section{A}

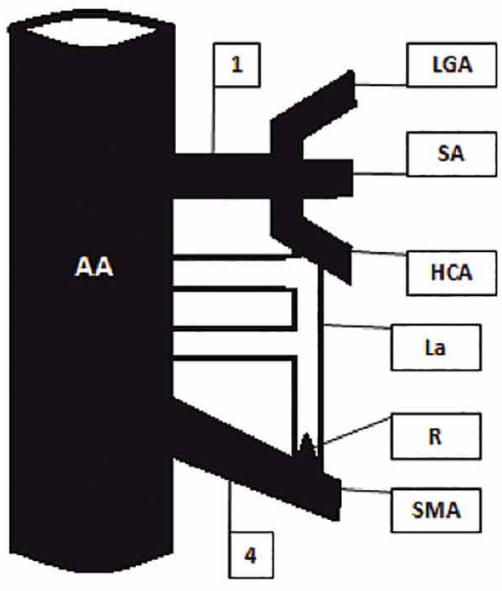

Fig. 4. A) A schematic drawing of the embryological development of the celiac trunk (1). The I and IV are the first roots of the omphalo-mesenteric trunk (Tandler 1904). A rudimentary branch (R) of the ventral langsanastomose (La). B) The embryological development of the gastrosplenic trunks (GST) and hepatomesenteric (HMT) according to Morita(1935). Anastomose (An) side-to-side between aberrant branch (Ab) and gastroduodenal artery (GDA). Left gastric artery (LGA); Splenic artery (SA); Common hepatic artery (CHA); Superior mesenteric artery (SMA) and Abdominal Aorta (AA). 


\section{DISCUSSION}

Knowledge about the irrigation territory of the celiac trunk and superior mesenteric artery, as well as of its variations, is essential in medical practice, especially for supramesocolic surgeries. Several investigators have classified the most common variations of these arteries: Eaton (1917) classified these arteries into 4 types, 4 classes and 15 forms, Adachi (1928) into 6 types with 28 groups, Tsukamoto (1929) into 9 types with 17 forms, Aso (1932) into 3 types with 6 forms, and Morita (1935) into 5 types with 15 forms. Yamaki et al., described a rare case in which the celiac trunk was absent and all vessels that normally arise from it originated directly from the aorta. On the other hand, Çiçekcibasi et al. (2005), observed a celiac trunk giving origin to all branches of the supramesocolic compartment. Thus, there are numerous variations in the pattern of origin of arteries that are responsible for vascularization of the supramesocolic compartment.

The anatomical variations of the celiac trunk are the result of changes that occur during the development of the ventral splanchnic arteries. The embryologic explanation for celiac trunk variations is based on the different possibilities of closure between the longitudinal anastomosis and the four branches of the omphalomesenteric artery described by Tandler (1904). On the basis of Tandler's theory, Morita classified the variation patterns of these arteries into 5 types and 15 forms. The variation described in the present study corresponds to celiacomesenteric type IV1 (Fig. 3), i.e., fusion between branches I and II and branches III and IV of the primitive ventral splanchnic arteries and simultaneous atrophy of the longitudinal anastomosis during embryo development (Fig. 4). This also explains the respective origins of the GST and HMT seen in the present study. However, the presence of an aberrant branch of marked caliber apparently originating from the splenic branch of the GST has not been reported in the literature. In addition, along its course and close to the duodenum, this branch anastomosed side-to-side with a branch that, theoretically, would correspond to the gastroduodenal artery originating from the hepatic branch of the HMT. On the basis of the descriptions of Morita, one may suggest the absence of complete atrophy of the longitudinal anastomosis. Its presumed persistence between the primitive ventral branches I and II resulted in an atypical origin of the right gastro-omental artery. In addition, a small remnant of the longitudinal anastomosis between branches III and IV and subsequent development of the gastroduodenal artery parallel to the right gastro-omental artery would also explain the anastomosis between these vessels (Figs. 4A and 4B). Thus, knowledge about the possible origins of anatomical variations in the arterial irrigation of the supramesocolic compartment is fundamental, especially for gastroduodenopancreatectomy as well as bariatric surgeries that are increasingly more common currently.

OKAMURA, A.; AlVAREZ, D.; GenOVEZ, P.; CAldeiRA, E. J.; DA CUNHA, M. R. \& CARVALHO, C. A. F. Un origen diferente de la arteria gastro-omental derecha. Int. J. Morphol., 33(4):1343-1347, 2015.

RESUMEN: La arteria gastro-omental es una de las ramas de la arteria hepática común. Las alteraciones en el desarrollo embrionario de las arterias ventrales pueden causar variaciones marcadas. Se observó una variante rara de la arteria gastro-omental derecha durante la disección de un cadáver de un hombre de 50 años de edad. La presencia de esta variante no se ha informado en la literatura especializada. Este caso de origen diferente de la arteria gastro-omental se describe detalladamente con el fin de proporcionar información que pueda contribuir a la cirugía abdominal superior.

PALABRAS CLAVE: Arteria gastro-omental derecha; Variación anatómica; Cirugía abdominal.

\section{REFERENCES}

Adachi, B. Das Arteriensystem der Japaner. Band II. Kyoto, Maruzen Publishing Co., 1928. pp.28-38.

Agarwal, A. K.; Youssef, M. K.; Doyle, G. J. \& Wood, C. P. Coeliomesenteric trunk stenosis--a rare variation causing mesenteric ischaemia. Eur. J. Vasc. Endovasc. Surg., 20(4):405-6, 2000.
Aso, S. Über das Gefäßsystem des Rumpfes bei japanischen Föten. Das Arteriensystem. Acta Anat. Nippon., 5:41-77, 1932.

Basar, R.; Onderogul, S.; Cumhur, T.; Yüksel, M. \& Olcer, T. Agenesis of the coeliac trunk: an angiographic case. Kaibogaku Zasshi, 70(2):180-2, 1995. 
Cavdar, S.; Sehirli, U. \& Pekin, B. Coeliacomesenteric trunk. Clin. Anat., 10(4):231-4, 1997.

Ciçekcibas si, A. E.; Uysal, I. I.; Seker, M.; Tuncer, I.; Büyükmumcu, M. \& Salbacak, A. A rare variation of the coeliac trunk. Ann. Anat., 187(4):387-91, 2005.

Detroux, M.; Anidjar, S. \& Nottin, R. Aneurysm of a common celiomesenteric trunk. Ann. Vasc. Surg., 12(1):78-82, 1998.

Eaton, P. B. The coeliac axis. Anat. Rec., 13(6):369-74, 1917.

Haller, A. V. Icones anatomicae, quibus praecipuae aliquae partes corporis humani delineatae proponuntur et arteriarum potissimum historia continetur. Göttingen, A. Vandenhoeck, 1756.

Harada, H.; Yamaki, K.; Doi, Y.; Hirata, T.; Saga, T.; Nishida, T.; Nishimura, H. \& Yoshizuka, M. An anomalous case of the gastro-hepatic and the spleno-mesenteric trunks independently arising from the abdominal aorta. Kurume Med. J., 44(3):23740, 1997.

Kahraman, G.; Marur, T.; Tanyeli, E. \& Yildirim, M. Hepatomesenteric trunk. Surg. Radiol. Anat., 23(6):433-5, 2001.

Michels, N. A. The hepatic, cystic and retroduodenal arteries and their relations to the biliary ducts with samples of the entire coeliacal blood supply. Ann. Surg., 133(4):503-24, 1951.

Morettin, L. B.; Baldwin-Price, H. K. \& Schreiber, M. H. Congenital absence of the coeliac axis trunk. Am. J. Roentgenol. Radium Ther. Nucl. Med., 95(3):727-30, 1965.

Morita, M. Reports and conception of three anomalous cases of the coeliac and the superior mesenteric arteries. Igaku Kenkyu, 9:1993-2006, 1935.

Nakamura, Y.; Miyaki, T.; Hayashi, S.; Limura, A. \& Itoh, M. Three cases of the gastrosplenic and the hepatomesenteric trunks. Okajimas Folia Anat. Jpn., 80(4):71-6, 2003.

Okada, S.; Ohta, Y.; Shimizu, T.; Nakamura, M. \& Yaso, K. A rare anomalous case of absence of the coeliac trunk--the left gastric, the splenic and the common hepatic arteries arose from the abdominal aorta independently. Okajimas Folia Anat. Jpn., 60(1):65-71, 1983.

Saeed, M.; Murshid, K. R.; Rufai, A. A.; Elsayed, S. E. \& Sadiq, M. S. Coexistence of multiple anomalies in the coeliacmesenteric arterial system. Clin. Anat., 16(1):30-6, 2003.

Shoumura, S.; Emura, S.; Utsumi, M.; Chen, H.; Hayakawa, D.; Yamahira, T. \& Isono, H. Anatomical study on the branches of the coeliac trunk (IV). Comparison of the findings with Adachi's classification. Kaibogaku Zasshi, 66(5):452-61, 1991.
Tandler, J. Über die Varietäten der Arteria coeliaca und deren Entwicklung. Anat. Hefte., 25:473-500, 1904.

Tsukamoto, N. Studies on the arterial system in the abdominal cavity of the Japanese. Acta Anat. Nippon., 2:780-829, 1929.

Vandamme, J. P. \& Bonte, J. The branches of the coeliac trunk. Acta Anat. (Basel), 122(2):110-4, 1985.

Williams, P. L.; Warwick, R.; Dyson, M. \& Bannister, L. H. Gray's Anatomy. 37th ed. Edinburgh, Churchill Livingstone, 1989. p.768.

Yamaki, K.; Tanaka, N.; Matsushima, T.; Miyazaki, K. \& Yoshizuka, M. A rare case of absence of the coeliac trunk: the left gastric, the splenic, the common hepatic and the superior mesenteric arteries arising independently from the abdominal aorta. Ann. Anat., 177(1):97-100, 1995.

Correspondence to:

Cesar Alexandre Fabrega Carvalho

Rua Francisco Telles, 250, Vila Arens

P.O. Box: 1295

CEP: $13202-550$ - Jundiaí

São Paulo

BRAZIL

Email: carvalhocaf@fmj.br

Received: 21-01-2013

Accepted: 06-09-2013 